\title{
BMC
}

Psychiatry

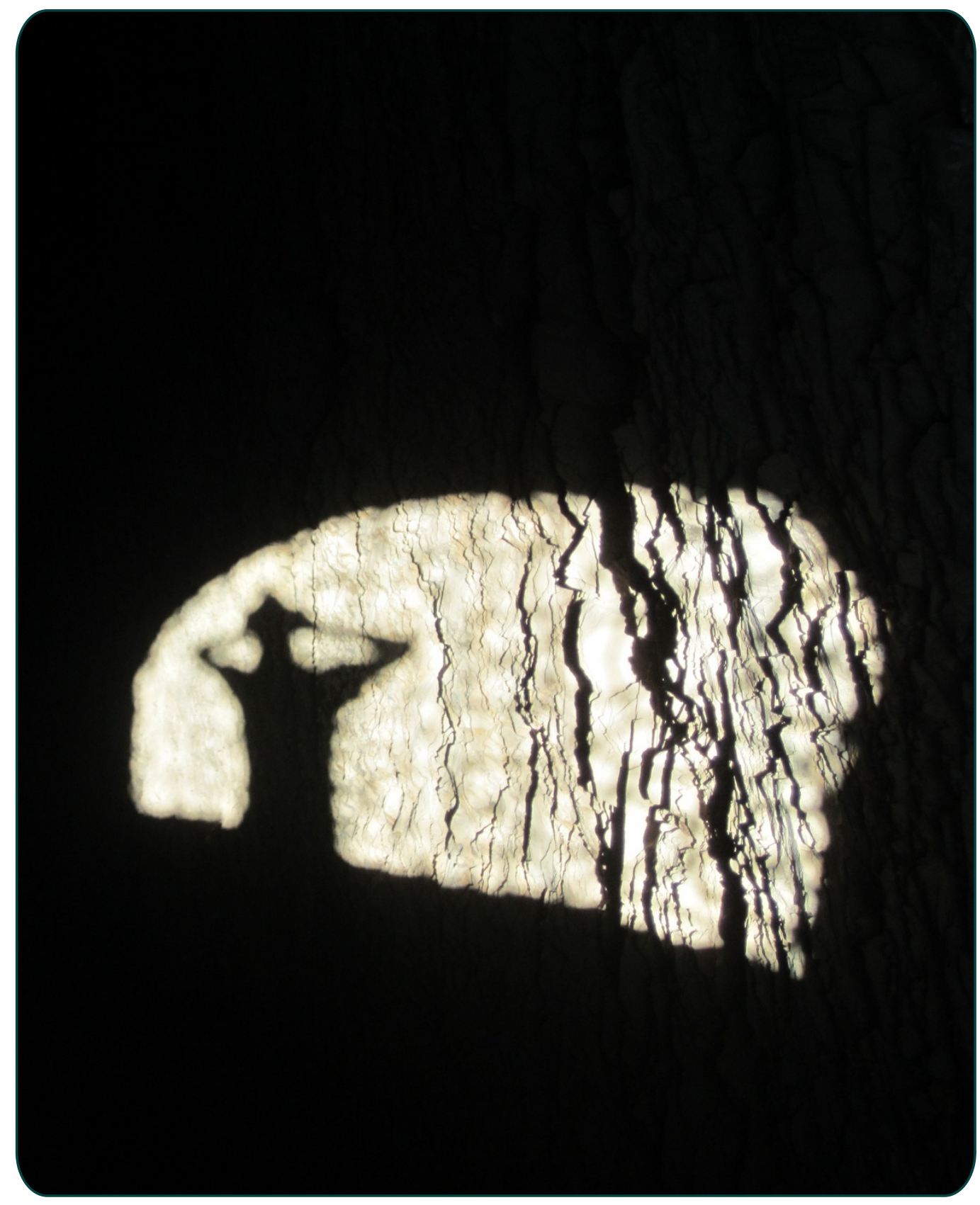

\section{Vitamin D status of psychiatric inpatients in New Zealand's Waikato region}

Menkes et al. 


\title{
Vitamin D status of psychiatric inpatients in New Zealand's Waikato region
}

\author{
David B Menkes ${ }^{1 *}$, Kaye Lancaster ${ }^{2}$, Michael Grant ${ }^{2}$, Reginald W Marsh ${ }^{1}$, Peter Dean² and Stephen A du Toit ${ }^{2}$
}

\begin{abstract}
Background: Vitamin D deficiency is widespread in New Zealand, confers multiple health risks, and may be particularly common among people with psychiatric illness. We studied vitamin D status in an unselected sample of adult psychiatric inpatients in Hamilton (latitude 37.5 S) during late winter.

Methods: We recruited 102 consenting subjects and measured 25-hydroxy vitamin D3 levels in venous blood using a competitive electrochemiluminescence immunoassay. In addition to descriptive statistics, we used one-sample ttests to determine the extent to which ethnic and diagnostic subgroups fell below the vitamin D deficiency threshold of $50 \mathrm{nM}$.
\end{abstract}

Results: 75 subjects (74\%) had vitamin D levels $<50 \mathrm{nM}$ and thus had at least mild deficiency, while 19 (19\%) were severely deficient with levels $<25 \mathrm{nM}$. Rates of deficiency were comparable for men and women; only the former showed a correlation of vitamin D levels with age $(r=0.45, p<0.01)$. Maori participants constituted half the sample $(n=51)$ and were more likely to be deficient than their European counterparts $(p=0.04)$. Vitamin $D$ also varied by diagnosis, with schizophrenia associated with markedly lower levels than mania and depression $(p<0.001)$.

Conclusions: Vitamin D deficiency is prevalent in the psychiatric inpatient setting in New Zealand and may be relevant to poor physical health outcomes, notably among Maori and those with schizophrenia. These findings support proposals to provide vitamin D supplementation, particularly during the winter months.

\section{Background}

Vitamin D plays a central role in the regulation of calcium status and is essential for bone health [1]. In the last decade, evidence has accumulated that vitamin $\mathrm{D}$ also has other important physiological roles, and is relevant to a variety of clinical conditions, including mental illness. For example, a Finnish cohort of boys receiving supplements during the first year of life showed a decreased risk of developing schizophrenia by age 31 [2]. Vitamin D also appears to influence mood symptoms, based on epidemiological [3] and clinical trial evidence [4].

There is some controversy regarding normal and optimal ranges for vitamin D. Because bone disease is clearly associated with blood levels $<25 \mathrm{nM}$, this threshold is generally accepted as indicating definite deficiency. Levels between 25 and $50 \mathrm{nM}$ are in a grey zone, commonly considered 'insufficiency', although some experts

\footnotetext{
* Correspondence: david.menkes@waikatodhb.health.nz

'Waikato Clinical School, Private Bag 3200, Hamilton 3240, New Zealand

Full list of author information is available at the end of the article
}

insist this still constitutes deficiency [5]. Optimum levels are now considered to be around $75 \mathrm{nM}$ and possibly higher $[1,6]$.

New Zealand's population appears to have widespread vitamin D deficiency [7-9]; based on its latitude (35-46 degrees $\mathrm{S}$ ) it is considered to be in a 'vulnerable' region [10] with marked seasonal fluctuations in ultraviolet light exposure. In addition, more than $30 \%$ of the population has darker skin pigmentation (14.6\% Maori; 9.2\% Asian; 6.9\% Pacific) [11] and among these populations vitamin $\mathrm{D}$ deficiency is likely to be even more common, as has been demonstrated in Maori compared to European children [8]. Sunscreen use is prevalent, reducing vitamin D synthesis, and there is little fortification of food [9] compared with North America and Western Europe. These regions also have prevalent deficiency despite repeated calls by authorities to increase the recommended intake of vitamin $\mathrm{D}$ [12].

Limited evidence indicates that vitamin D deficiency is common in psychiatric inpatient samples in Germany [13], the UK [14] and Australia [15]; corresponding data

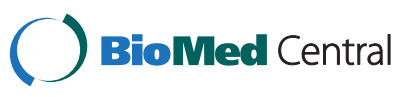


from New Zealand have not been reported. However indirect evidence indicates that deficiency is likely to be, if anything, worse than in the general population. Mental disorder is associated with poor diet and limited outdoor exercise, thus tending to limit vitamin D intake and synthesis. Moreover, those with darker skin, particularly Maori, tend both to have higher rates of deficiency and also to be over-represented in psychiatric inpatient populations [16]. Based on the foregoing, we aimed to measure vitamin D levels in psychiatric patients in Hamilton, New Zealand (latitude $37.5^{\circ} \mathrm{S}$ ) during the late winter when levels are near their nadir [7,17]. Our secondary aims were to investigate the possible role of ethnicity and diagnosis in rates of vitamin D deficiency in this population.

\section{Methods}

\section{Subjects and recruitment}

The eligible population included 132 adult patients (1865 years) admitted to the region's inpatient psychiatric facility between 29 July and 31 August 2010. 102 (78\% of those eligible) gave informed consent and had serum samples collected by venepuncture. Ethnicity was determined according to the New Zealand Census procedure 2001, with particular attention paid to evidence of Maori identity by descent. Clinical diagnosis was established at hospital discharge based on DSM-IV criteria. The study was approved by the Northern Y Regional Ethics Committee (NTY/10/EXP/061).

\section{Biochemistry}

Plasma 25-hydroxy vitamin D3 was determined using a competitive electrochemiluminescence immunoassay (E170, Roche diagnostics, Mannheim, Germany). Cross reactivity with 25-hydroxy vitamin D2 and with 24,25dihydroxy vitamin $\mathrm{D}$ is less than $10 \%$ and $20 \%$ respectively. The coefficient of variation is $<8 \%$ at each concentration of internal control (35, 50 and $75 \mathrm{nM})$. Samples were analysed by the Waikato Hospital laboratory, certified by the relevant international accreditation agency (www.ianz.govt.nz/). By consensus in New Zealand (www.bpac.org.nz/magazine/2011/june/vitamin-d.asp), and in accord with studies mentioned in the Introduction, this laboratory defines levels between 25-50 nM (10-20 ng/ml) and those below $25 \mathrm{nM}(10 \mathrm{ng} / \mathrm{ml})$ as indicating mild and severe deficiency, respectively.

\section{Data analysis}

Data were collected using an Excel spreadsheet and analysed using SPSS version 19. One-sample tests were used to determine the extent to which ethnic and diagnostic subgroups fell below the vitamin D deficiency threshold of 50 nM. Parametric correlations and partial correlations were calculated to estimate the effect of age, and Fisher's Exact
Test to identify differences in deficiency rates by category (gender, ethnicity, diagnosis). Cross-tabulation and Cramer's V test were used to determine the association of psychiatric diagnoses with ethnicity.

\section{Results}

The final sample included 102 subjects, of whom 56 were men and 51 were of Maori ethnicity. Vitamin D levels varied from 10 - $170 \mathrm{nM}$; mean values by gender, ethnicity, and diagnosis are presented in Table 1. Suboptimal levels $(<75 \mathrm{nM})$ were detected in $91 \%$ of subjects, and at least mild deficiency $(<50 \mathrm{nM})$ in $74 \%$, with comparable proportions of men (70\%) and women (76\%). Severe deficiency $(<25 \mathrm{nM})$ was seen in $19 \%$ overall ( $16 \%$ of men and $22 \%$ of women, $p=0.61$, Fisher's Exact Test). There was thus no gender effect regarding overall rates of vitamin D deficiency, but there was a Sex $\mathrm{x}$ Age interaction, with men showing significant positive relationship $(\mathrm{r}=0.45, \mathrm{p}<0.01)$ not seen among women $(\mathrm{r}=0.11, \mathrm{p}<0.5)$. Maori men, however, were younger than their non-Maori counterparts by 4 years on average. A partial correlation was calculated to examine the possible role of ethnicity in the observed age effect for men. The resulting comparable correlation $\left(r_{\text {parti }}=0.424\right.$, $\mathrm{p}=0.002$ ) indicates that the age effect is independent of ethnicity.

An ethnic difference in rates of vitamin D deficiency was identified based on 51 patients with verified Maori identity; 14 of these were severely deficient $(<25 \mathrm{nM})$ compared to $5 / 51$ of non-Maori ( $p=0.04$, Fisher's Exact Test, see Table 2 ). As shown in Table 1, mean levels in the Maori group were significantly lower than the non-Maori (mean difference $=$ 9.7 $\mathrm{nM}, 95 \% \mathrm{CI}=1.4$ to $18.0, \mathrm{t}=2.33, \mathrm{p}=0.022$ ). Onesample statistics showed that Maori were, on average, significantly below the $50 \mathrm{nM}$ deficiency threshold

Table 1 Association of vitamin D levels with gender, ethnicity and diagnosis

\begin{tabular}{|c|c|c|c|c|c|}
\hline \multirow[t]{2}{*}{ Group } & \multirow[t]{2}{*}{$n$} & \multicolumn{2}{|c|}{ vitamin D (nM) } & \multicolumn{2}{|c|}{ one-sample test } \\
\hline & & mean & s.d. & $\mathbf{t}$ & $\mathbf{p}$ \\
\hline Entire sample & 102 & 42.7 & 21.5 & 3.45 & .001 \\
\hline Male & 56 & 42.6 & 20.2 & 2.73 & .008 \\
\hline Female & 46 & 42.7 & 23.2 & 2.14 & .04 \\
\hline Maori & 51 & 37.8 & 20.3 & 4.29 & $<.001$ \\
\hline Non-Maori & 51 & 47.5 & 21.7 & 0.82 & .42 \\
\hline Schizophrenia & 38 & 34.5 & 15.4 & 6.23 & $<.001$ \\
\hline Schizoaffective & 11 & 42.8 & 9.00 & 2.65 & .024 \\
\hline Bipolar Disorder & 19 & 49.4 & 29.2 & 0.09 & .93 \\
\hline Depression & 17 & 47.5 & 25.7 & 0.40 & .70 \\
\hline Miscellaneous & 17 & 48.4 & 20.6 & 0.32 & .75 \\
\hline
\end{tabular}

One sample t-tests were used to estimate the extent to which vitamin D levels in the study population and sub-groups differed from the deficiency threshold of $50 \mathrm{nM}$. 
Table 2 Vitamin D deficiency rates by diagnostic group, ethnicity, and gender

\begin{tabular}{|c|c|c|c|c|c|c|}
\hline \multirow[t]{2}{*}{ Group } & \multicolumn{4}{|c|}{$\frac{\text { count by Vitamin D level }}{\underline{(\mathrm{nM})}}$} & \multicolumn{2}{|c|}{$\frac{\% \text { less than }}{\text { (nM) }}$} \\
\hline & all & $>50$ & $25-50$ & $<25$ & 50 & 25 \\
\hline Entire sample & 102 & 27 & 56 & 19 & 73.5 & 18.6 \\
\hline $\begin{array}{l}\text { Schizophrenia } \\
\text { spectrum }\end{array}$ & 49 & 7 & 29 & 13 & 85.7 & 26.5 \\
\hline Maori & 34 & 3 & 20 & 11 & 91.2 & 32.3 \\
\hline male & 20 & 3 & 11 & 6 & 85.0 & 30.0 \\
\hline female & 14 & 0 & 9 & 5 & 100 & 35.7 \\
\hline non-Maori & 15 & 4 & 9 & 2 & 73.3 & 13.3 \\
\hline male & 10 & 4 & 4 & 2 & 60.0 & 20.0 \\
\hline female & 5 & 0 & 5 & 0 & 100 & 0.0 \\
\hline Other diagnoses & 53 & 20 & 27 & 6 & 62.3 & 11.3 \\
\hline Maori & 17 & 4 & 10 & 3 & 76.5 & 17.6 \\
\hline male & 10 & 3 & 5 & 2 & 70.0 & 20.0 \\
\hline female & 7 & 1 & 5 & 1 & 85.7 & 14.3 \\
\hline non-Maori & 36 & 16 & 17 & 3 & 55.6 & 8.3 \\
\hline male & 16 & 6 & 9 & 1 & 62.5 & 6.3 \\
\hline female & 20 & 10 & 8 & 2 & 50.0 & 10.0 \\
\hline
\end{tabular}

Cases were assigned to categories according to vitamin $\mathrm{D}$ level; percentages with mild $(<50 \mathrm{nM})$ and severe $(<25 \mathrm{nM})$ deficiency are summarized in the right hand columns.

$(95 \% \mathrm{CI}=-17.9$ to $-6.5, \mathrm{t}=4.29, \mathrm{p}<0.001)$ whereas the same was not true of non-Maori.

Vitamin D levels were also found to vary by diagnosis, as shown in Table 1. Among the 19 participants with severe deficiency $(<25 \mathrm{nM}), 13$ had a diagnosis of schizophrenia. This equates to $34 \%$ of participants with that diagnosis, compared to $9.4 \%$ of other participants $(\mathrm{n}=102, \mathrm{p}=0.003$, Fisher's Exact Test). Taken together, disorders in the schizophrenia spectrum (schizophrenia and schizoaffective disorder) were over-represented among those with Vitamin D deficiency (Table 2) and had markedly reduced average levels $(\mathrm{n}=49$, mean $=36.4$ $\mathrm{nM}$, one-sample $\mathrm{t}=6.58, \mathrm{p}<0.001$ ) compared to the other diagnostic groups, none of which showed a mean difference from the deficiency threshold of $50 \mathrm{nM}$ (Table 1).

As is apparent in Table 2, Maori appear overrepresented in disorders in the schizophrenia spectrum, raising the question of to what extent the effects of ethnicity and diagnosis, described above, may be confounded. We first conducted a cross-tabulation of diagnosis by ethnicity, confirming a highly significant association of Maori ethnicity with schizophrenia and schizoaffective disorder in our inpatient sample (Cramer's $V=0.415, \mathrm{p}<0.001$, $\mathrm{n}=102$ ). Comparing ethnicities within the schizophrenia spectrum showed Maori to have a lower mean vitamin $\mathrm{D}$ level $(34.0 \pm 14.3 \mathrm{nM}, \mathrm{n}=34)$ than Europeans $(41.6 \pm 14.1$ $\mathrm{nM}, \mathrm{n}=15)$ but this difference failed to reach statistical significance $(t=1.71, p=0.093, d f=47)$. Based on this small sample, it thus appears that Maori ethnicity and schizophrenia are associated with each other, and both contribute to low vitamin D.

Given the finding of excess vitamin D deficiency in schizophrenia, we hypothesized that this might arise from patients with this diagnosis spending relatively less time outdoors. Lacking a specific index of an individual's sun exposure, we examined time in hospital as a proxy measure. For each participant, we determined days in hospital during the 180 days preceding vitamin D sampling and found a weak relationship in the expected direction between hospitalisation and vitamin $\mathrm{D}(\mathrm{r}=-0.18$, $\mathrm{n}=102, \mathrm{p}=0.072$ ). Also as expected, patients with schizophrenia and schizoaffective disorder had been on average hospitalised longer (mean $=24.7 \pm 41.9$ days) than other diagnoses (mean $=13.2 \pm 29.5$ days, $t=1.59$, $\mathrm{p}=0.12$ ) but this difference was not significant and cannot account for the striking association of diagnosis with vitamin D.

\section{Discussion}

Our results indicate a substantial frequency of vitamin D deficiency in a New Zealand inpatient psychiatric population, and accord with evidence of widespread deficiency in the country generally [7-9], and in psychiatric samples overseas [13-15]. In the southern province of Canterbury, the population is generally exposed to less ultraviolet light than Waikato - being an average of 7 degrees further from the equator. A careful epidemiological study in Canterbury found an $89 \%$ rate of at least mild deficiency $(<50 \mathrm{nM})$ and $35 \%$ severe deficiency $(<25 \mathrm{nM})$ during winter (7). These rates are higher than in our clinical sample, although there is no available Waikato norm for comparison. It is thus possible that our results reflect the general Waikato population.

Previous studies performed in nearby Auckland (latitude $36.5^{\circ} \mathrm{S}$ compared to Hamilton $37.5^{\circ} \mathrm{S}$ ) $[17,18]$ found vitamin $\mathrm{D}$ deficiency to be more frequent in women than men; in our sample there was only a slight, insignificant excess of women with severe deficiency. Our sample of younger and middle-aged adults (18-65) did however show a correlation of vitamin D levels with age in men but not women, as was found in a Swedish study [19]. This may explain why the Auckland studies, which focused on older adults, found significantly higher levels in men.

We found lower mean vitamin D levels among Maori (Table 1), who were also more than twice as likely as Europeans to have severely deficient levels below $25 \mathrm{nM}$ (Table 2). The generally darker Polynesian skin colour may explain this effect, as was suggested for the comparable difference found in New Zealand children [8]. Low vitamin $D$ is associated with an increased risk of 
metabolic syndrome, diabetes, and cardiovascular events $[20,21]$; this may be of particular relevance to Maori whose already elevated cardiometabolic risk appears exacerbated by antipsychotic treatment [22].

Individuals with vitamin D levels below $25 \mathrm{nM}$ may benefit from supplementation, particularly with regard to cardiovascular and bone health [20,21,23], but it is unclear to what extent deficiency and its remediation may affect our patients' mental disorder. In the case of mood disorder there is suggestive evidence that it may be helpful based on the reported epidemiological association between low vitamin $\mathrm{D}$ levels and depressive symptoms [24] and positive results from a trial of supplementation [4].

The observed excess of vitamin D deficiency among patients with schizophrenia and schizoaffective disorder is intriguing. While their slightly greater time in hospital cannot account for this difference, it may be that these patients are generally less likely to spend time outdoors and thus synthesize less of the vitamin. Another possibility, suggested by in vitro studies but yet to verified in patients, is that antipsychotic drug treatment may inhibit vitamin D synthesis [25]. Previous clinical studies have produced mixed results; one found excess vitamin D deficiency in schizophrenia and autism compared to other outpatient diagnoses [19], another reported comparably reduced vitamin D in inpatient schizophrenia and depression [13] and a third showed no difference between patients with psychosis and matched controls [26]. It remains a possibility that vitamin $\mathrm{D}$ abnormalities in early life are associated with the pathogenesis of schizophrenia [2,27].

Many countries have high rates of vitamin $\mathrm{D}$ deficiency, despite mandatory fortification of foods in, for example, North America, Western Europe, and Australia. Such a policy is yet to be implemented in New Zealand. Supplementation is inexpensive, around \$1 per month, and is reported to have few side effects and little toxicity [28] even when large doses are used [29]. At the behest of a government agency (the Accident Compensation Corporation), elderly rest home populations in New Zealand are now routinely supplemented with vitamin $D$ in order to reduce the risk of falls causing fractures and other injuries [23]. There are, as yet, no guidelines on supplementation of psychiatric patients in New Zealand.

\section{Conclusions}

The observed prevalence of vitamin D deficiency in our psychiatric inpatient population supports the idea that supplementation should be more generally available, and perhaps routinely prescribed, given its low cost, lack of adverse effects and multiple potential benefits. It is our experience that 'natural therapies' are popular with psychiatric patients; this may facilitate uptake of such treatment, at least during inpatient admission. Supplementation may be of particular benefit to Maori and to patients with schizophrenia; both groups have characteristically poor physical health outcomes and were found in this study to have exceptionally low vitamin D levels.

Competing interests

The authors declare they have no competing interests.

\section{Acknowledgements}

We thank Drs Leong Leow and Eleni Nikolau for discussions, and the staff of the Henry Rongomau Bennett Centre, Waikato Hospital, for logistical and moral support. This work was supported by a Mental Health Research Fund grant from the Waikato District Health Board. The funder played no role in the design or conduct of the study, or in the decision to submit the manuscript for publication.

\section{Author details}

${ }^{1}$ Waikato Clinical School, Private Bag 3200, Hamilton 3240, New Zealand. ${ }^{2}$ Waikato District Health Board, Pembroke Street, Hamilton 3240, New Zealand.

\section{Authors' contributions}

$\mathrm{KL}, \mathrm{PD}, \mathrm{SD}$ and $\mathrm{DM}$ developed to the original idea and design of the study. $\mathrm{KL}$ and MG gained staff support, recruited participants, and collected data; MG also determined ethnicity. SD organized chemical assays, quality control, and reporting. RM conducted the statistical analysis. DM was responsible for overall organization of the study and drafting the manuscript. All authors contributed to editing and approving the final version.

\section{Authors' information}

David B Menkes, consultant psychiatrist and associate professor Kaye Lancaster, psychiatric nurse

Michael Grant, trainee psychiatrist of Maori (Te Arawa) ethnicity Reginald W Marsh, statistician/epidemiologist and honorary associate professor

Peter Dean, consultant forensic psychiatrist

Stephen A du Toit, consultant chemical pathologist

Received: 25 October 2011 Accepted: 26 June 2012

Published: 26 June 2012

\section{References}

1. Thacher TD, Clarke BL: Vitamin D insufficiency. Mayo Clin Proc 2011, 86:50-60.

2. McGrath J, Saari $K$, Hakko H, Jokelainen J, Jones $P$, Järvelin M-R, Chant D, Isohanni $M$ : Vitamin D supplementation during the first year of life and risk of schizophrenia: a Finnish birth cohort study. Schizophr Res 2004, 67:237-245.

3. Ganji V, Milone C, Cody MM, McCarty F, Wang YT: Serum vitamin D concentrations are related to depression in young adult US population: the Third National Health and Nutrition Examination Survey. Int Arch Med 2010, 3:29.

4. Jorde R, Sneve M, Figenschau Y, Svartberg J, Waterloo K: Effects of vitamin D supplementation on symptoms of depression in overweight and obese subjects: randomized double blind trial. J Intern Med 2008, 264:599-609.

5. Holick MF: Vitamin D deficiency. N Engl J Med 2007, 357:266-281.

6. Pearce SH, Cheetham TD: Diagnosis and management of vitamin D deficiency. BMJ 2010, 340.

7. Livesey J, Elder P, Ellis MJ, McKenzie R, Liley B, Florkowski C: Seasonal variation in vitamin $D$ levels in the Canterbury, New Zealand population in relation to available UV radiation. N Z Med J 2007, 120:U2733.

8. Rockell JE, Green TJ, Skeaff CM, Whiting SJ, Taylor RW, Williams SM, Parnell WR, Scragg R, Wilson N, Schaaf D, et al: Season and Ethnicity Are Determinants of Serum 25-Hydroxyvitamin D Concentrations in New Zealand Children Aged 5-14 y. J Nutr 2005, 135:2602-2608.

9. Whiting SJ, Green TJ, Calvo MS: Vitamin D intakes in North America and Asia-Pacific countries are not sufficient to prevent vitamin D insufficiency. J Steroid Biochem Mol Biol 2007, 103:626-630.

10. Kimlin MG: Geographic location and vitamin D synthesis. Mol Aspects Med 2008, 29:453-461. 
11. QuickStats About Culture and Identity. In QuickStats About Culture and Identity. Wellington: New Zealand Government 2006.

12. Vieth R, Bischoff-Ferrari H, Boucher BJ, Dawson-Hughes B, Garland CF, Heaney RP, Holick MF, Hollis BW, Lamberg-Allardt C, McGrath JJ, et al: The urgent need to recommend an intake of vitamin $D$ that is effective. Am J Clin Nutr 2007, 85:649-650.

13. Schneider B, Weber B, Frensch A, Stein J, Fritz J: Vitamin D in schizophrenia, major depression and alcoholism. J Neural Transm 2000, 107:839-842.

14. Tiangga E, Gowda A, Dent JA: Vitamin D deficiency in psychiatric in-patients and treatment with daily supplements of calcium and ergocalciferol. Psychiatric Bulletin 2008, 32:390-393.

15. Berk M, Jacka FN, Williams LJ, Ng F, Dodd S, Pasco JA: Is this D vitamin to worry about? Vitamin D insufficiency in an inpatient sample. Aust N Z J Psychiatry 2008, 42:874-878.

16. Wheeler A, Robinson E, Robinson G: Admissions to acute psychiatric inpatient services in Auckland, New Zealand: a demographic and diagnostic review. N Z Med J 2005, 118:U1752.

17. Bolland MJ, Grey AB, Ames RW, Mason BH, Horne AM, Gamble GD, Reid IR: Determinants of vitamin D status in older men living in a subtropical climate. Osteoporos Int 2006, 17:1742-1748.

18. Lucas JA, Bolland MJ, Grey AB, Ames RW, Mason BH, Horne AM, Gamble GD, Reid IR: Determinants of vitamin D status in older women living in a subtropical climate. Osteoporos Int 2005, 16:1641-1648.

19. Humble MB, Gustafsson S, Bejerot S: Low serum levels of 25-hydroxyvitamin D (25-OHD) among psychiatric out-patients in Sweden: relations with season, age, ethnic origin and psychiatric diagnosis. J Steroid Biochem Mol Biol 2010, 121:467-470.

20. Pittas AG, Chung M, Trikalinos T, Mitri J, Brendel $M$, Patel $K$, Lichtenstein $A H$, Lau J, Balk EM: Systematic review: Vitamin D and cardiometabolic outcomes. Ann Intern Med 2010, 152:307-314.

21. Wang TJ, Pencina MJ, Booth SL, Jacques PF, Ingelsson E, Lanier K, Benjamin EJ, D'Agostino RB, Wolf M, Vasan RS: Vitamin D deficiency and risk of cardiovascular disease. Circulation 2008, 117:503-511.

22. Cameron MJ, Singh R, Leathart A, Puckey NW, Menkes DB: Metabolic syndrome in Maori and Pakeha treated with antipsychotic drugs. NZ Medical Journal 2009, 122:107.

23. Janssen HC, Samson MM, Verhaar HJ: Vitamin D deficiency, muscle function, and falls in elderly people. Am J Clin Nutr 2002, 75:611-615.

24. Ganji V, Zhang X, Shaikh N, Tangpricha V: Serum 25-hydroxyvitamin D concentrations are associated with prevalence of metabolic syndrome and various cardiometabolic risk factors in US children and adolescents based on assay-adjusted serum 25-hydroxyvitamin D data from NHANES 2001-2006. Am J Clin Nutr 2011, 94:225-233.

25. Lauth M, Rohnalter $V$, Bergstrom A, Kooshesh M, Svenningsson $P$, Toftgard R: Antipsychotic drugs regulate hedgehog signaling by modulation of 7-dehydrocholesterol reductase levels. Mol Pharmacol 2010, 78:486-496.

26. McGrath JJ, Kimlin MG, Saha S, Eyles DW, Parisi AV: Vitamin D insufficiency in south-east Queensland. Med J Aust 2001, 174:150-151.

27. McGrath J, Brown A, St Clair D: Prevention and schizophrenia-the role of dietary factors. Schizophr Bull 2011, 37:272-283.

28. Holick MF: The D-lemma: to screen or not to screen for 25hydroxyvitamin D concentrations. Clin Chem 2010, 56:729-731.

29. Bacon CJ, Gamble GD, Horne AM, Scott MA, Reid IR: High-dose oral vitamin D3 supplementation in the elderly. Osteoporos Int 2009, 20:1407-1415

\section{Submit your next manuscript to BioMed Central and take full advantage of:}

- Convenient online submission

- Thorough peer review

- No space constraints or color figure charges

- Immediate publication on acceptance

- Inclusion in PubMed, CAS, Scopus and Google Scholar

- Research which is freely available for redistribution

Submit your manuscript at www.biomedcentral.com/submit
Ciomed Central 